\title{
Taurine and inflammatory diseases
}

\author{
Janusz Marcinkiewicz $\cdot$ Ewa Kontny
}

Received: 24 April 2012/ Accepted: 3 July 2012 / Published online: 19 July 2012

(C) The Author(s) 2012. This article is published with open access at Springerlink.com

\begin{abstract}
Taurine (2-aminoethanesulfonic acid) is the most abundant free amino acid in humans and plays an important role in several essential biological processes such as bile acid conjugation, maintenance of calcium homeostasis, osmoregulation and membrane stabilization. Moreover, attenuation of apoptosis and its antioxidant activity seem to be crucial for the cytoprotective effects of taurine. Although these properties are not tissue specific, taurine reaches particularly high concentrations in tissues exposed to elevated levels of oxidants (e.g., inflammatory cells). It suggests that taurine may play an important role in inflammation associated with oxidative stress. Indeed, at the site of inflammation, taurine is known to react with and detoxify hypochlorous acid generated by the neutrophil myeloperoxidase (MPO)-halide system. This reaction results in the formation of less toxic taurine chloramine $(\mathrm{TauCl})$. Both haloamines, $\mathrm{TauCl}$ and taurine bromamine ( $\mathrm{TauBr}$ ), the product of taurine reaction with hypobromous acid $(\mathrm{HOBr})$, exert antimicrobial and anti-inflammatory properties. In contrast to a well-documented regulatory role of taurine and taurine haloamines ( $\mathrm{TauCl}, \mathrm{TauBr}$ ) in acute inflammation, their role in the pathogenesis of inflammatory diseases is not clear. This review summarizes our current knowledge concerning the role of taurine, $\mathrm{TauCl}$ and $\mathrm{TauBr}$ in the pathogenesis of inflammatory diseases initiated or propagated by MPO-derived oxidants. The aim of this paper is to show links between inflammation,
\end{abstract}

J. Marcinkiewicz ( $\square)$

Department of Immunology, Jagiellonian University Medical

College, 18 Czysta St., 31-121 Kraków, Poland

e-mail: mmmarcin@cyf-kr.edu.pl

E. Kontny

Department of Pathophysiology and Immunology,

Institute of Rheumatology, Warsaw, Poland neutrophils, MPO, oxidative stress and taurine. We will discuss the possible contribution of taurine and taurine haloamines to the pathogenesis of inflammatory diseases, especially in the best studied example of rheumatoid arthritis.

Keywords Taurine - Taurine chloramine .

Taurine bromamine $\cdot$ Inflammatory diseases .

Rheumatoid arthritis · Neutrophils .

Myeloperoxidase $\cdot$ Antioxidants

\section{Introduction}

Acute inflammation is a physiological response of tissues to harmful stimuli such as pathogens, damaged cells or cancer cells and irritants. This response, mediated predominantly by innate immunity, is responsible for elimination of these injurious stimuli and for the subsequent healing process. The major cells involved in acute inflammation are neutrophils: phagocytes responsible for microbial killing and for generation of various proinflammatory mediators. The myeloperoxidase-halide system plays a unique role in killing pathogens phagocytosed by neutrophils (Klebanoff 1968, 2005) through generation of hypochlorous acid $(\mathrm{HOCl})$, a potent microbicidal and cytotoxic oxidant (Thomas 1979). Remarkably, MPO is the only mammalian enzyme that oxidizes $\mathrm{Cl}^{-}$into $\mathrm{HOCl}$ (Gaut et al. 2001). Moreover, MPO can also oxidize $\mathrm{Br}^{-}$to produce hypobromous acid (HOBr) (Thomas et al. 1995). Upon contact with a pathogen, activated phagocytes (both neutrophils and macrophages) produce a respiratory burst characterized by intense uptake of oxygen. Oxidant production begins when a membrane-associated NADPH oxidase reduces molecular oxygen to superoxide, which 


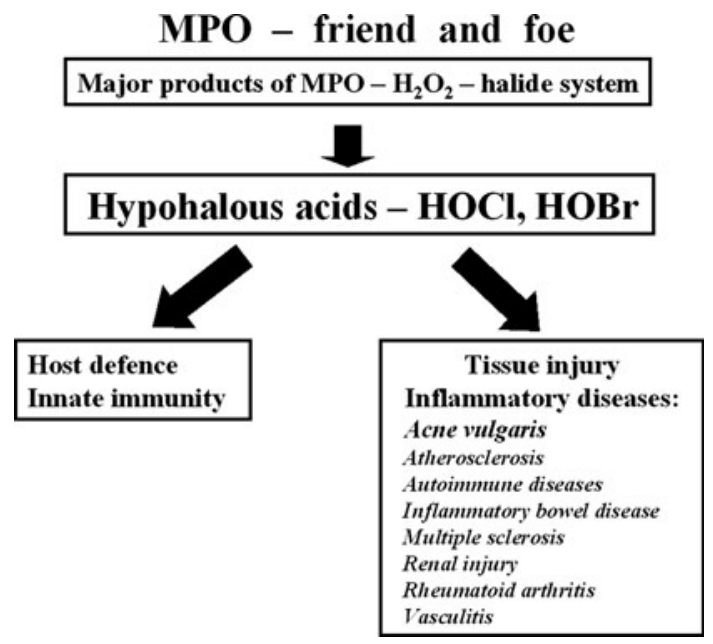

Fig. 1 Hypohalous acids, the major products of PO-halide system exert both a beneficial (microbicidal) and detrimental (tissue injury) role in neutrophil-associated inflammation

then yields $\mathrm{H}_{2} \mathrm{O}_{2}$. In neutrophil phagolysosomes, myeloperoxidase (MPO) uses $\mathrm{H}_{2} \mathrm{O}_{2}$ to convert chloride ion to $\mathrm{HOCl}$, or bromide ion to $\mathrm{HOBr}$ (Klebanoff 1968; Thomas 1979; Henderson et al. 2001)

$\mathrm{Cl}^{-}+\mathrm{H}_{2} \mathrm{O}_{2}+\mathrm{H}^{+} \rightarrow \mathrm{HOCl}+\mathrm{H}_{2} \mathrm{O}$,

$\mathrm{Br}^{-}+\mathrm{H}_{2} \mathrm{O}_{2}+\mathrm{H}^{+} \rightarrow \mathrm{HOBr}+\mathrm{H}_{2} \mathrm{O}$.

Both hypohalous acids, $\mathrm{HOCl}$ and $\mathrm{HOBr}$, are components of innate immunity and protect the host from infections by using their oxidizing potential to kill pathogens, but they may also damage host tissue. The microbicidal effects of $\mathrm{HOCl}$ have been linked to oxidation of methionine residues in bacterial cytosolic and inner membrane proteins (Rosen et al. 2009). On the other hand, overproduction of these oxidants and insufficient neutralization by antioxidants may lead to the development of oxidative stress and chronic inflammation (Smith 1994; Weiss 1988). Such a scenario may contribute to pathogenesis of inflammatory diseases, in which the neutrophil MPO-halide system is involved (Fig. 1). The above information clearly suggests that antioxidants play a crucial role in maintaining homeostasis and in amelioration of the harmful effect of oxidative stress. We asked the question whether taurine and/or taurine haloamines play a role in the pathogenesis of inflammatory diseases. We will focus on the role of $\mathrm{TauCl}$ in the regulation of inflammation in rheumatoid arthritis, the best studied diseases in our laboratories (Marcinkiewicz and Kontny 2012).

\section{Taurine links to inflammation and oxidative stress}

Taurine, a semi-essential sulfur-containing $\beta$-amino acid, is present at high concentrations in most cells of all animal

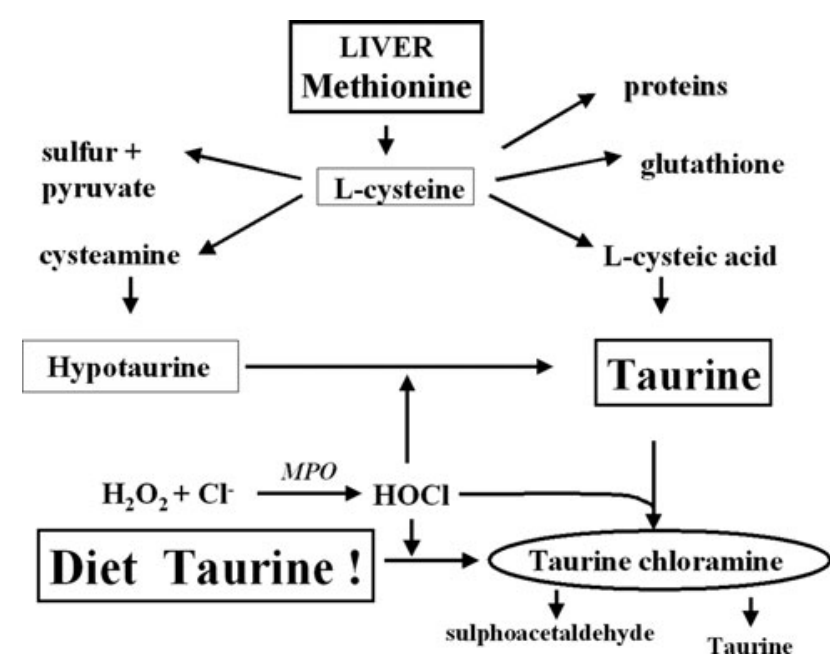

Fig. 2 Fate of endogenous and diet taurine in activated neutrophils

species (Sturmann 1993). In humans, taurine is formed from methionine and cysteine metabolism via hypotaurine in hepatocytes. Other cells (e.g., neutrophils) contain very high concentrations of taurine due to taurine uptake from the blood, a source of both endogenous and diet taurine (Fig. 2) (Bouckenooghe et al. 2006).

Taurine tissue distribution is characterized by low concentrations of taurine in the plasma and extracellular fluids (ranging from 10 to $100 \mu \mathrm{M}$ ) and high intracellular concentrations of taurine reaching up to $50 \mathrm{mM}$, depending on the cell type (Huxtable 1992; Learn et al. 1990). The biosynthetic capacity of humans to produce taurine is limited in neonates (the effect amplified by prematurity) and also declines with aging and some pathological stages (trauma, sepsis). In these situations, the diet is likely to be an important taurine source (Redmond et al. 1998).

The high taurine levels in phagocytes and accumulation in taurine inflammatory lesions suggests its role in innate immunity (Schuller-Levis and Park 2004). Activated phagocytes generate a variety of microbicidal and toxic oxidants produced by the peroxidase system in these cells. As taurine is present at high concentrations in leukocytes, one may hypothesise that taurine deficiency will affect the immune cell functions. Indeed, prolonged taurine deficiency in cats leads to profound abnormalities in the immune system including significant leukopenia, a decreased respiratory burst in neutrophils and depletion of cells from B cell areas of lymph nodes and spleen (Schuller-Levis et al. 1990). However, there is no clear evidence concerning the association between taurine deficiency and a defect of the immune system in humans. On the other hand, it is commonly accepted that taurine plays an important role in the immune system as an antioxidant to protect cells, including leukocytes, from oxidative stress (Schaffer et al. 2009; Wang et al. 2009). Therefore, the 


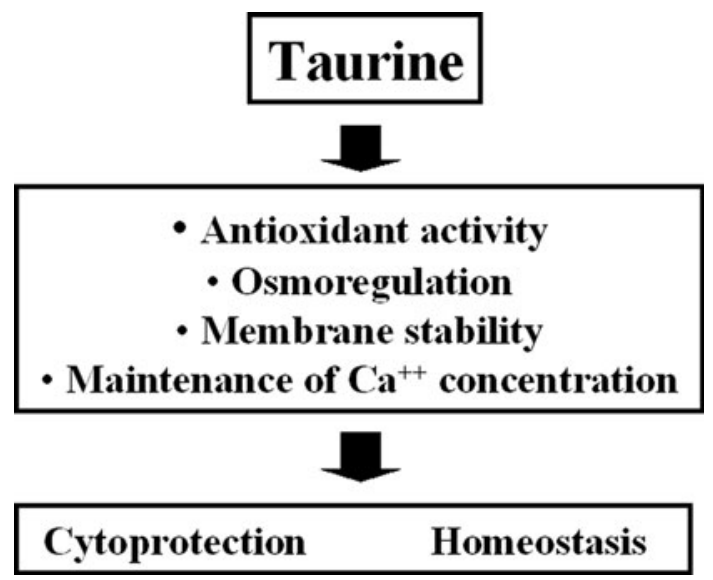

Fig. 3 Biological functions of intracellular taurine and the immune cells

primary role of taurine is cytoprotection and maintaining homeostasis of cells involved in acute and chronic inflammatory/oxidative stress (Fig. 3).

Oxidative stress is a major factor responsible for tissue damage in conditions such as infection, acute and chronic inflammation, cancer and aging. At a site of inflammation, oxidative stress is mediated by reactive oxygen species (ROS) generated primarily by activated leukocytes (neutrophils, macrophages, eosinophils). ROS play a beneficial role in host defense against pathogens, but they are also responsible for tissue injury (Weiss 1988; Smith 1994). A variety of antioxidants are involved in the prevention of oxidant-induced cell damage and reduction of oxidative modification of self-molecules, primarily high molecular compounds such as lipids, proteins and DNA. Antioxidants (the antioxidant network) act through one of three mechanisms: (1) reduction of ROS generation, (2) neutralization of ROS and (3) interference with the action of ROS (Schaffer et al. 2009).

Taurine is found at particularly high concentrations in tissues exposed to elevated levels of oxidants, suggesting its role in the attenuation of oxidative stress (Green et al. 1991; Jeon et al. 2009; Oliveira et al. 2010). Indeed, there have been numerous reports indicating taurine as an effective antioxidant, but the mechanism underlying its antioxidant activity remains unclear. The best established antioxidant action of taurine is neutralization of hypochlorous acid $(\mathrm{HOCl})$, an extremely toxic oxidant generated by the MPO-halide system (Weiss et al. 1982). This activity explains the anti-inflammatory properties of taurine, as its reaction with $\mathrm{HOCl}$ results in generation of taurine chloramine ( $\mathrm{TauCl})$, a more stable and less toxic anti-inflammatory mediator (Weiss et al. 1982; Thomas 1979) (Fig. 4).

Therefore, taurine may be considered the component of innate immunity with a special impact on the development

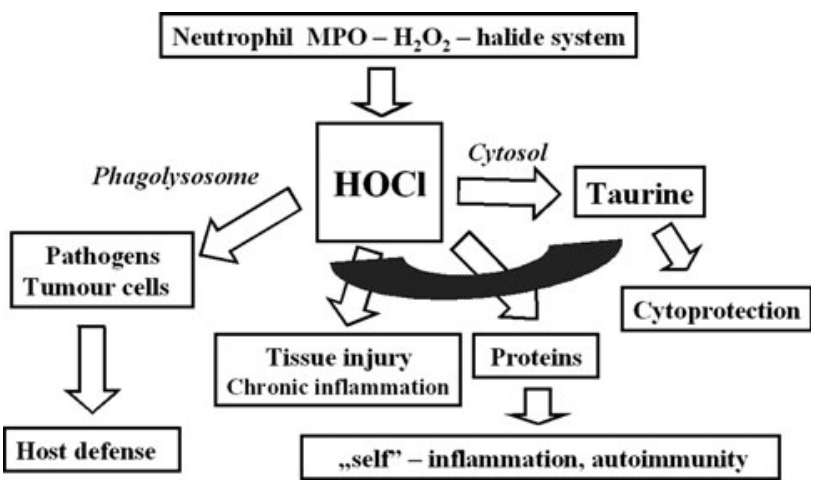

Fig. 4 Targets of $\mathrm{HOCl}$ at a site of inflammation and its interaction with taurine. Inside phagolysosomes, $\mathrm{HOCl}$ kills ingested microbes. Outside phagolysosomes, taurine neutralizes detrimental effects of $\mathrm{HOCl}$ on neighboring cells and protects "self" molecules from oxidative modification. $\mathrm{TauCl}$, the product of this reaction, is less toxic than $\mathrm{HOCl}$. TauCl is not membrane permeable, oxidizes distinct targets and causes less damage to biologically active molecules (Marcinkiewicz and Kontny 2012)

of acute inflammation. However, not all of the antioxidant actions of taurine are related to $\mathrm{HOCl}$, because they can occur in systems lacking neutrophils. Although taurine is incapable of directly scavenging classical ROS, it has been suggested that it is an effective inhibitor of ROS generation. It has been shown that taurine enhances expression and activities of antioxidant enzymes, such as superoxide dismutase, catalase and glutathione peroxidase (Jang et al. 2009).

In conclusion, the data presented above suggest that the major role of taurine in the immune system is associated with taurine's antioxidant properties, namely, with its ability to react with $\mathrm{HOCl}$ or $\mathrm{HOBr}$ to generate the biologically active but less toxic mild oxidants taurine chloramine $(\mathrm{TauCl})$ and taurine bromamine $(\mathrm{TauBr})$, respectively

Taurine $+\mathrm{HOCl} \rightarrow$ taurine chloramine $+\mathrm{H}_{2} \mathrm{O}$,

Taurine $+\mathrm{HOBr} \rightarrow$ taurine bromamine $+\mathrm{H}_{2} \mathrm{O}$.

\section{Taurine haloamines (TauCl, TauBr): a role in host defense}

$\mathrm{TauCl}$ and $\mathrm{TauBr}$ antimicrobial capacity

It is well known that oxidants generated by phagocytes at a site of inflammation are involved in host defense against microbes. Among them, hypohalous acids $(\mathrm{HOCl}, \mathrm{HOBr})$, extremely strong microbicidal agents, play a crucial role in killing of pathogens by neutrophils and eosinophils. They can kill a wide spectrum of Gram-positive and Gram-negative bacteria, fungi (yeast and molds), viruses, protozoa and worm larvae (Klebanoff 1968; Weiss 1988; Thomas et al. 1995). TauCl and $\mathrm{TauBr}$, the physiological 
products of the MPO-halide system, show bactericidal, fungicidal, antiviral and antiparasitic properties, as demonstrated in vitro in a number of papers (Nagl et al. 2000b, 2001; Gottardi et al. 2005; Marcinkiewicz et al. 2000, 2006a; Yazdanbakhsh et al. 1987).

$\mathrm{TauCl}$, the product of activated neutrophils, reaches micromolar concentrations $(<100 \mu \mathrm{M})$ at the site of inflammation. At these physiological concentrations and at neutral $\mathrm{pH}, \mathrm{TauCl}$ shows very weak antimicrobial activity. However, in acidic milieu which is typical for an inflammatory environment ( $\mathrm{pH} 4-6$ ), the ability of $\mathrm{TauCl}$ to kill pathogens increases significantly due to formation of the more potent $\mathrm{TauCl}_{2}$ (taurine dichloramine). $\mathrm{TauCl}_{2}$ is more bactericidal than $\mathrm{TauCl}$, especially against Gram-negative bacteria, probably due to better penetration into bacteria. In addition, transfer of the active chlorine (transchlorination) from $\mathrm{TauCl}$ to amino groups of other molecules enhances its activity, mainly because of the formation of monochloramine $\left(\mathrm{NH}_{2} \mathrm{Cl}\right)$ (Gottardi et al. 2005; Gottardi and Nagl 2010; Nagl et al. 2003). However, it has not been proven whether endogenous $\mathrm{TauCl}$ also contributes to the killing of microbes in vivo. On the other hand, exogenous $\mathrm{TauCl}$ proved to be extremely well tolerated by human tissues and even $1 \%$ aqueous solution of $\mathrm{TauCl}$ may be applied locally in the treatment of some skin and mucous infections (Gottardi and Nagl 2010).

$\mathrm{TauBr}$, in contrast to $\mathrm{TauCl}$, seems to be an effective microbicidal agent at very low physiologic concentrations $<10 \mu \mathrm{M}$, even at neutral $\mathrm{pH}$ (Marcinkiewicz et al. 2006a, b). These results suggest that $\mathrm{TauBr}$ may contribute to host defense against microbes, although this still needs to be confirmed in vivo.

Importantly, the data investigating $\mathrm{TauCl}$ and $\mathrm{TauBr}$ antimicrobial activity in vitro have all been collected using planktonic form of bacteria, but not sessile bacteria hidden in a biofilm. Recently, there has been a tremendous interest in the role of biofilms in chronic infectious diseases and in the resistance of biofilms to antibiotics, disinfectants and phagocytosis (Costeron et al. 1991). As microbial biofilms are the most common mode of growth of bacteria and fungi in nature (O'Toole et al. 2000), it is reasonable to study whether $\mathrm{TauCl}$ and $\mathrm{TauBr}$ are able to kill bacteria hidden in a biofilm or destroy a protective exopolymeric matrix of growing biofilms. Our preliminary data suggest that taurine haloamines, especially $\mathrm{TauBr}$, are promising candidates in the local therapy of biofilm-associated infections such as chronic sinusitis, otitis media, acne vulgaris and periodontal diseases.

\section{Anti-inflammatory properties of $\mathrm{TauCl}$ and $\mathrm{TauBr}$}

Acute inflammation is characterized by a massive neutrophil infiltration and generation of a variety of inflammatory mediators such as cytokines, eicosanoids and ROS (Weiss 1988; Thomas 1979). Studies from many laboratories have demonstrated that taurine haloamines ( $\mathrm{TauCl}, \mathrm{TauBr})$ exert both bactericidal and anti-inflammatory properties (Park et al. 1993, 1995; Marcinkiewicz et al. 1995b, 1998, 2000, 2005; Quinn et al. 2003; Kim et al. 1996; Kim and Cha 2009). Taurine haloamines inhibit the production of proinflammatory cytokines (TNF- $\alpha$, IL-1 $\beta$ and IL-6) (Marcinkiewicz et al. 1995a; Park et al. 1997; Barua et al. 2001). Moreover, it has been shown that $\mathrm{TauCl}$ reduces the production of nitric oxide $(\mathrm{NO})$ and prostaglandin $\mathrm{E}_{2}$ $\left(\mathrm{PGE}_{2}\right)$ and decreases the activity of matrix metalloproteinases (Chorazy-Massalska et al. 2004; Park et al. 2000; Kim et al. 2007). The above-mentioned anti-inflammatory properties together with the capacity of $\mathrm{TauCl}$ to induce leukocyte apoptosis suggest that $\mathrm{TauCl}$ may be involved in the resolution and termination of acute inflammation (Klamt and Shacter 2005). Interestingly, taurine, in contrast to $\mathrm{TauCl}$, protects cells from apoptosis as shown in a number of in vitro studies (Jong et al. 2011; Maher et al. 2005).

Impact of $\mathrm{TauCl}$ and $\mathrm{TauBr}$ on the induction of antioxidant network

It is well documented that taurine protects cells against oxidative injury (Schaffer et al. 2009). In acute inflammation, which is characterized by neutrophil infiltration and generation of ROS by the MPO-halide system, taurine antioxidant activity is primarily related to the neutralization of $\mathrm{HOCl}$ and $\mathrm{HOBr}$, as described above. It is also well known that $\mathrm{TauCl}$ and $\mathrm{TauBr}$, apart from antimicrobial and anti-inflammatory properties, may also show antioxidantlike biological effects (Park et al. 1995; Marcinkiewicz et al. 1995b, 1998). TauCl and $\mathrm{TauBr}$ suppress the activity of phagocytic cells, thereby reducing their ability to consume oxygen and induce respiratory burst. In addition, $\mathrm{TauCl}$ reduces the production of ROS by increasing the expression of peroxyredoxin-1 and thioredoxin-1, the antioxidant enzymes normally induced by the activation of NF-E2-related factor-2 (Nrf2) (Kim et al. 2010a, b). Moreover, $\mathrm{TauCl}$ and $\mathrm{TauBr}$, in a similar, dose-dependent manner, significantly enhanced in vitro the expression of heme-oxygenase-1 (HO-1) in various cells (Olszanecki and Marcinkiewicz 2004; Olszanecki et al. 2008; Kim et al. 2010a, b; Marcinkiewicz et al. 2009). The induction of HO-1 plays an especially important role in tissue homeostasis, as the products of HO-1-mediated heme degradation regulate important biological processes including oxidative stress and inflammation (Wagener et al. 2003). In addition, HO-1 reduces synthesis of proinflammatory heme proteins such as COX-2 and iNOS (Ryter et al. 2002). Therefore, one may speculate that at a site of inflammation, $\mathrm{TauCl}$ 


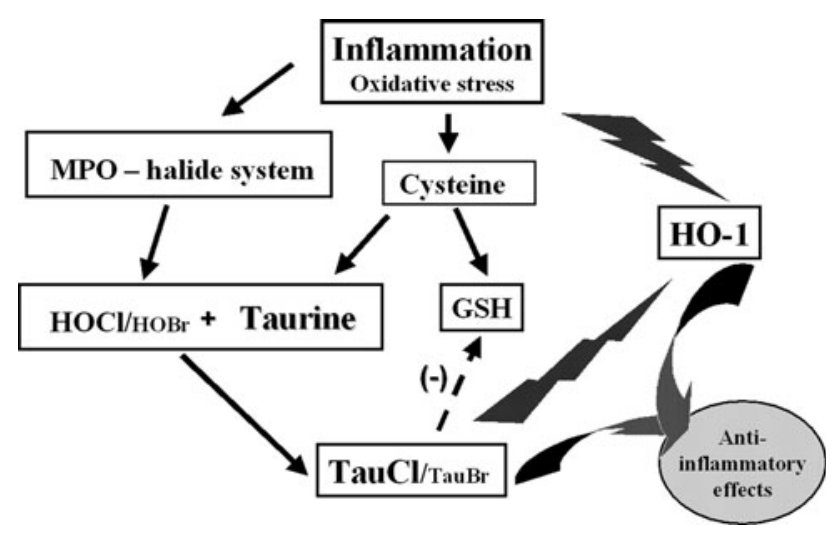

Fig. 5 Association of taurine with the antioxidant network: a redundancy of the immune system. Taurine haloamines, the products of MPO-halide system, function as a physiological link between cysteine pathway and the heme-oxygenase-1 system (HO-1)

and/or TauBr will induce HO-1 in neighboring non-activated cells to protect them against oxidative stress (Fig. 5).

\section{Taurine and taurine derivatives in inflammatory diseases: their role in pathogenesis and treatment of MPO-associated chronic inflammation}

The antimicrobial and anti-inflammatory properties of $\mathrm{TauCl}$ and $\mathrm{TauBr}$ make these agents good candidates for clinical use, especially for local treatment of infectious/ inflammatory diseases (Gottardi and Nagl 2010; Marcinkiewicz 2009). So far, the therapeutic efficacy of these agents has been shown in acne vulgaris, external otitis, purulently coated crural ulcerations and keratoconjunctivitis (Gottardi et al. 2005, 2007; Marcinkiewicz et al. 2008; Nagl et al. 2000a, b, 2003; Neher et al. 2007). Moreover, it has been suggested that $\mathrm{TauCl}$ may be of potential benefit as adjunctive local therapy in periodontal diseases (Mainnemare et al. 2004). In contrast to the successful topical therapies mentioned above, rapid degradation of $\mathrm{TauCl}$ and $\mathrm{TauBr}$ in the blood limits their systemic application (Martini et al. 2012). As systemic therapy with taurine haloamines seems to be impossible, an alternative, novel strategy may be to administer taurine itself as a prodrug. Taurine supplementation may be predicted to enhance local formation of $\mathrm{TauCl}$ or $\mathrm{TauBr}$, as exogenous taurine will react with endogenous $\mathrm{HOCl} / \mathrm{HOBr}$. Such strategies may be effective in inflammatory conditions associated with local infiltration of neutrophils, for example chronic sinusitis, inflammatory bowel disease and rheumatoid arthritis. So far, the beneficial effect of such strategy has been documented in experimental colitis treated with 5-aminosalicyltaurine (taurine conjugated with 5-ASA) (Kim et al. 2006; Joo et al. 2009), in dextran sulfate sodium (DSS)-induced experimental colitis in mice attenuated by dietary taurine supplementation (Shimizu et al. 2009) and in collagen-induced arthritis treated with taurolidine (Marcinkiewicz et al. 2006a, b). The precise mechanism underlying the beneficial effects of the dietary taurine supplementation is still unclear and remains to be explained.

In conclusion, both in vitro and clinical studies clearly indicate that both, taurine and taurine derivatives, may find their place in the therapy for various topical infections as well as chronic inflammatory diseases. In the next section, we will discuss the role of MPO-halide system products, namely $\mathrm{TauCl}$ in the pathogenesis of rheumatoid arthritis, the best studied model of inflammatory disease in our laboratories.

Taurine and taurine derivatives in rheumatoid arthritis (RA) and collagen-induced arthritis (CIA)

Rheumatoid arthritis (RA) is a chronic systemic autoimmune disorder affecting approximately $1 \%$ of the population and leading eventually to joint deformation, dysfunction and disability in most diseased individuals. The etiology and pathogenesis of RA are not fully understood. However, genetic (e.g., genes encoding HLA-DR molecules containing shared epitopes) and environmental factors (e.g., Porphyromonas gingivalis infection) are generally accepted as participating in disease development, while repeated activation of innate immunity and deregulated adaptive immunity are thought to contribute to inflammation chronicity and self-tolerance breakdown (Gregersen et al. 1987; Detert et al. 2010; Gierut et al. 2010; Scherer and Burmester 2011). Numerous cytokines, released primarily by cells that accumulate in the synovium (e.g., synoviocytes, infiltrating leucocytes), play a fundamental role in these pathological processes.

Novel biological therapies (cytokine antagonists, B cell depletion, $\mathrm{T}$ cell co-stimulatory blockers) markedly improved RA patients' clinical outcomes, but impressive efficacy is only reached in about half of them (Scott 2012). Therefore, great efforts are made to indicate the new therapeutic targets.

Pathological processes in rheumatoid arthritis joints

In a normal joint, the lining layer of the joint cavity (synovium) is composed of intimal lining and sublining formed by cells submerged in a bed of extracellular matrix (ECM). Macrophage-like (MfLS) and fibroblast-like (FLS) synoviocytes are present in the synovial intimal lining, where MfLS clear the joint from microorganisms and cellular debris, while FLS synthesize ECM and synovial fluid components. Rheumatic joints are characterized by synovial 
membrane inflammation (synovitis) and progressive damage to the articular cartilage and subchondral bone (Firestein 2009; Bartok and Firestein 2010). The number of MfLS and FLS rises dramatically and the intimal lining expands from $1-2$ cells depth to a depth of up to 10-20 cells. Both types of rheumatoid synoviocytes display a highly activated phenotype and represent the major source of locally synthesized pro-inflammatory factors and enzymes degrading connective tissue. Moreover, synoviocytes form niches for infiltrating immune cells. By secretion of soluble factors as well as direct cell-to-cell interaction via adhesion molecules, synoviocytes support survival and differentiation of $\mathrm{T}$ and $\mathrm{B}$ lymphocytes into pathogenic Th17 subset and plasma cells, respectively. Lymphocytes and dendritic cells massively infiltrate the sublining layer and form ectopic lymphoid tissue, where autoantibodies are produced. Neutrophils pass through the synovium and accumulate in RA synovial fluid, where their number is extremely high, reaching up to $5 \times 10^{9}$ cells. It is well known that neutrophils recruited into the site of inflammation generate a large number of highly reactive oxidants, including hypochlorous acid ( $\mathrm{HOCl})$. This highly reactive oxidant is immediately consumed and thus inactivated by reaction with the thiol groups of cellular proteins and proteins originating from engulfed pathogens, as well as by transferring of the active chlorine to amino groups. Neutrophils contain a large amount of taurine, which represents about $50 \%$ of the cellular amino acid pool. Therefore, this dominant free amino acid is the key molecule able to trap $\mathrm{HOCl}$. Reaction of $\mathrm{HOCl}$ with taurine results in the formation of taurine chloramine $(\mathrm{TauCl})$, endowed with potent anti-inflammatory properties, as described above. Due to prolonged activation, neutrophils accumulating in rheumatoid synovial fluid exhibit features indicative of partial functional "exhaustion". Importantly, these cells generate less $\mathrm{TauCl}$ in vitro than their peripheral blood counterparts, suggesting that the local concentration of $\mathrm{TauCl}$ in RA joints is probably too low to exert antiinflammatory effects (Kontny et al. 2002). Thus, diminished local generation of $\mathrm{TauCl}$ may contribute to more complex immunoregulatory disturbances related to the chronic course of inflammatory response in RA joints.

As a result of the above events, rheumatoid synovium transforms to a hyperplastic, invasive tissue. At the cartilage-bone interface, this expansive tissue, called pannus, invades the cartilage and erodes into the bone. Due to their unique invasive properties and production of huge amount of proteases, FLS are the primary effectors of cartilage degradation. Progressive bone damage results from resorption of this tissue by osteoclasts and its inefficient restoration by osteoblasts (Schett et al. 2011).

We have recently reported that also rheumatoid articular adipose tissue (AAT) is also highly reactive and upon stimulation secretes considerable amounts of pro- inflammatory (IL-1 $\beta$, IL-6, IL-8, TNF- $\alpha$ ) and anti-inflammatory (IL-1 receptor antagonist-IL-1Ra) cytokines as well as classical adipokines (leptin, adiponectin). Moreover, we found this tissue to release biologically active factors that intensify the pathogenic activities of rheumatoid FLS. Thus, AAT should be considered a novel important contributor to the pathological processes taking place in the RA joints (Kontny et al. 2012).

Taurine chloramine normalizes pathogenic functions of rheumatoid FLS

Among numerous factors secreted by FLS, VEGF and IL-8 recruit immune cells and support angiogenesis, $\mathrm{PGE}_{2}$ mediates vascular phase of inflammatory response and osteoclastic bone resorption, while IL-6 exerts pleiotropic effects, e.g., supports differentiation of T helper lymphocytes into Th17 subset, participates in bone loss and contributes to systemic symptoms. In vitro studies revealed that at physiologically relevant concentrations $(200-500 \mu \mathrm{M})$, $\mathrm{TauCl}$ inhibits synthesis of these factors by several mechanisms: (1) acting at the transcriptional level, (2) diminishing DNA-binding activity of $\mathrm{NF} \kappa \mathrm{B}$ and $\mathrm{AP}-1$ transcription factors or (3) up-regulating heme-oxygenase-1 (Kontny et al. 1999, 2000, 2003a, b, 2007; Muż et al. 2008). Another taurine derivative with potential immunoregulatory activity, taurine bromamine ( $\mathrm{TauBr}$ ), is less effective in normalization of these pro-inflammatory rheumatoid FLS properties (Kontny et al. 2007). Moreover, in these cells $\mathrm{TauCl}$ down-regulates also expression of collagenases (MMP-1, MMP-13) that play a dominant destructive role in RA (Kim et al. 2007, 2010a, b). Furthermore, TauCl inhibits proliferation of RA FLS and renders these cells more sensitive to death (Kontny et al. 2006a, b). Thus, in vitro TauCl dampens several activities of rheumatoid FLS relevant to the contribution of these cells to local pathological processes, i.e., inflammation support, joint destruction and synovial hyperplasia.

Interestingly, neither taurine alone nor sulfoacetaldehyde, a product of $\mathrm{TauCl}$ decomposition, exerts such suppressive effects on RA FLS (Kontny et al. 2003c). Thus, the unique activities of $\mathrm{TauCl}$ arise from its oxidative properties and selective modification of molecules implicated in cellular signal transduction pathways (Kontny et al. 2000; Kim et al. 2007; Muż et al. 2008).

Taurine chloramine exerts immunomodulatory effect on the secretory activity of rheumatoid joint-associated adipose tissue

We have recently reported that not only synovium but also articular adipose tissue, organized into the largest Hoffa infrapatellar fat pad and three smaller fat pads, is a rich 
source of adipokines and other factors that participate in local pathological processes characteristic for RA (Kontny et al. 2012). In patients with osteoarthritis, articular adipose tissue is infiltrated by immune cells (monocytes, granulocytes, T lymphocytes) (Klein-Wieringa et al. 2011). The activity of cells present in the rheumatoid synovium is supported not only by locally produced cytokines and growth factors, but also by direct cell-to-cell interactions. Thus, the inhibitory effect of $\mathrm{TauCl}$ on isolated FLS does not entirely reproduce in situ circumstances. To mimic in vivo conditions, we examined the effect of $\mathrm{TauCl}$ on the secretory activity of these joint tissues. Tissue specimens of articular adipose tissue (AAT; $n=35-63$ ), periarticular subcutaneous adipose tissue (ScAT; $n=19-25$ ) and synovial membrane (SM; $n=17-25$ ) were obtained from knee joint of patients $(60 \mathrm{~F} / 3 \mathrm{M})$ with established RA (RA stages III-IV) at the time of total joint surgery, performed as a normal part of clinical care. Subcutaneous adipose tissue was taken from the site of the suture. All patients gave their informed consent and the study was approved by the Institute of Rheumatology Ethics Committee. The mean (range) patient's age and disease duration was 55.3 (26-68) and 17 (6-34) years, respectively. Tissue preparation and cultures were performed as described previously (Kontny et al. 2012). Tissue explants $(100 \mathrm{mg} / \mathrm{ml})$ were cultured in Dulbecco's modified Eagle medium (DMEM/ $50 \mu \mathrm{g} / \mathrm{ml}$ gentamicin $/ 100 \mathrm{mg} / \mathrm{ml}$ kanamycin) alone, or stimulated for $18 \mathrm{~h}$ with $1 \mu \mathrm{g} / \mathrm{ml}$ of lipopolysaccharide from Escherichia coli 055:B5 (LPS, Difco, Detroit, MI, USA) in the presence or absence of $500 \mu \mathrm{M}$ TauCl. The concentrations of selected pro- and anti-inflammatory cytokines and classical adipokines in culture supernatants were measured by specific ELISA, as described previously (Kontny et al. 2012). IL-10 concentrations were measured using commercially available set (eBioscience, San Diego, CA, USA). Taurine chloramine ( $N$-chlorotaurine sodium salt), was a gift from prof. Waldemar Gottardi and prof. Marcus Nagl from the Division of Hygiene and Medical Microbiology, Innsbruck Medical University, Austria. Data were analyzed using Statistica vol. 7.0 software. The Wilcoxon test was applied to evaluate the effect of LPS and LPS + TauCl. Differences were considered significant for $* p<0.05, * * p<0.01$ and $* * * p<0.001$.

As shown in Figs. 6 and 7, both AAT and ScAT produced spontaneously smaller amounts of cytokines than $\mathrm{SM}$, but cytokine release from all tested tissues rose significantly in the presence of LPS, known to activate cells via toll-like receptor 4 . We used ScAT as a control tissue, but unexpectedly it responded to LPS treatment similarly to AAT, showing that adipose tissue, at least from these locations, was highly reactive to this pro-inflammatory stimulus. In LPS-treated adipose explant cultures, the addition of $\mathrm{TauCl}$ significantly inhibited the production of
IL-6, TNF- $\alpha$ and IL-8 ( $\%$ of inhibition was $\approx 60,25$ and $26 \%$, respectively). However, in equivalent SM cultures, only the secretion of IL- 6 and IL- 8 was diminished (by 23-25\%), but the reduction of IL-8 release did not reach statistical significance. By contrast, in all tissue cultures, LPS-triggered release of anti-inflammatory IL-10 was not significantly affected upon $\mathrm{TauCl}$ treatment (Fig. 6).

Interleukin $1 \beta$ is another pro-inflammatory cytokine which plays a critical role in RA pathogenesis. The biological activity of IL- $1 \beta$ is counteracted by IL-1Ra, but for successful blockade a large molecular excess (100-fold to 1,000 -fold) of IL-1Ra is required (Gabay et al. 2010). As shown in Fig. 7, all tested tissues secreted spontaneously higher amounts of IL-1Ra than IL- $1 \beta$. However the IL-1Ra/IL- $\beta$ ratio was higher in AAT and ScAT than in SM cultures, suggesting that in adipose tissue IL- $1 \beta$ activity is better controlled. In all tissue cultures, LPS markedly elevated both IL- $1 \beta$ and IL-1Ra release, leading to a dramatic decrease of IL-1Ra/IL- $1 \beta$ ratio. In the presence of $\mathrm{TauCl}$, significantly reduced secretion of both IL-1 $\beta$ and IL-1Ra was observed and thus IL-1Ra/IL-1 $\beta$ ratio was not restored (Fig. 7).

It has been suggested that also classical adipokines also participate in RA pathogenesis, but their role is still controversial. Leptin is structurally classified as a member of the long-chain helical cytokine family, which includes several pro-inflammatory cytokines, e.g., IL-6 and IL-12. Both pro- and anti-inflammatory properties of leptin have been described (Stofkova 2009; Neumann et al. 2011). Adiponectin structurally belongs to the collagen superfamily and shares homologies with the collagens, complement factors and TNF- $\alpha$. Adiponectin has effects in a number of different tissues, e.g., it counteracts insulin resistance in muscle, reduces atherosclerosis, as well as prevents the deleterious effects of TNF- $\alpha$ on endothelial cells by reducing adhesion molecule expression and inflammation (Gustafson 2010). In contrast in RA, adiponectin appears to demonstrate mostly pro-inflammatory and pro-destructive effects (Frommer et al. 2010; Neumann et al. 2011). Adiponectin exists in several forms (globular and multimers of high and low molecular weight) that differ in biological activities (Gustafson 2010). Unfortunately, the relevance of these adiponectin forms to RA pathological processes is unknown.

Interestingly, the expression and release of adipokines is reciprocally regulated by inflammatory stimuli. Acute inflammation and pro-inflammatory cytokines (TNF- $\alpha$, IL1, IL-6) positively regulate leptin expression and its circulating levels, whereas long-term exposition to IL- 1 or TNF- $\alpha$ exerts negative effects. By contrast, the same pro-inflammatory cytokines are potent inhibitors of adiponectin gene expression or protein secretion (Stofkova 2009). As shown in Fig. 8, spontaneous secretion of leptin and adiponectin 
Fig. 6 Effect of $\mathrm{TauCl}$ on proand anti-inflammatory cytokine release from articular adipose tissue (AAT), subcutaneous $(S c A T)$ adipose tissue and synovial membrane $(S M)$ explants. Tissue explants were cultured for $18 \mathrm{~h}$ in $37{ }^{\circ} \mathrm{C}$ in culture medium alone (control; white bars) or treated with LPS $(1 \mu \mathrm{g} / \mathrm{ml})$ in the absence (black bars) or presence of $\mathrm{TauCl}$ $(500 \mu \mathrm{M})($ gray bars $)$, then cytokine concentrations in culture supernatants were measured by ELISA. Values are the mean and SEM of 35-53 (AAT), 20-25 (ScAT) or 14-24 (SM) experiments. *Indicates statistically significant differences between untreated and treated cultures; ${ }^{\#}$ Indicates statistically significant differences between LPSversus LPS + TauCl-treated cultures; ${ }^{*, \#} p<0.05$ **,\#\# $p<0.01 ; * * *$,\#\#\# $p<0.001$
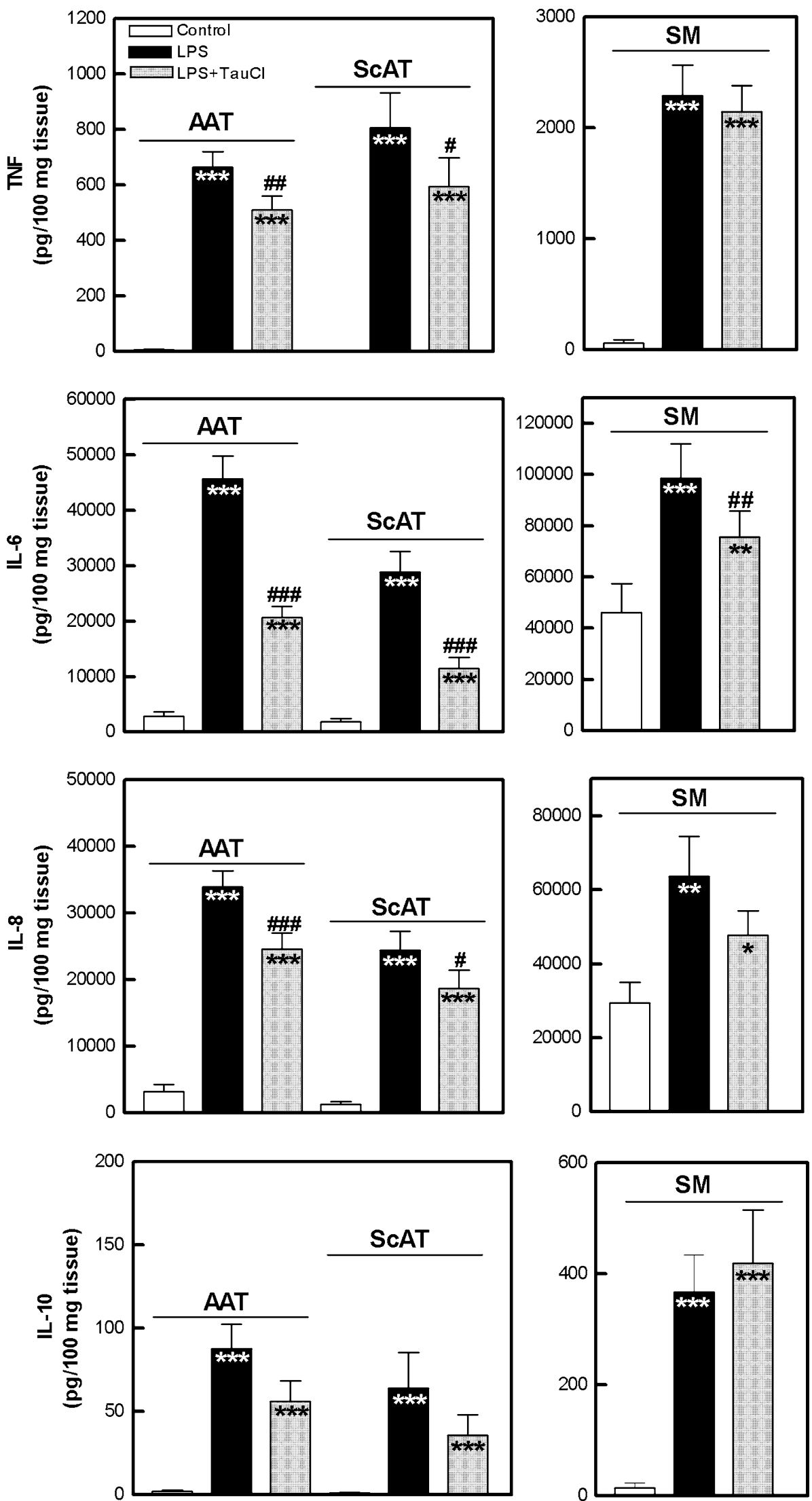
Fig. 7 Effect of $\mathrm{TauCl}$ on IL-1 $\beta$ and IL-1Ra release from articular adipose tissue (AAT), subcutaneous $(S c A T)$ adipose tissue and synovial membrane $(S M)$ explants. Explanations as in Fig. 1. Values are the mean and SEM of 37-41 (AAT), 19-23 (ScAT) or 17-18 (SM) experiments
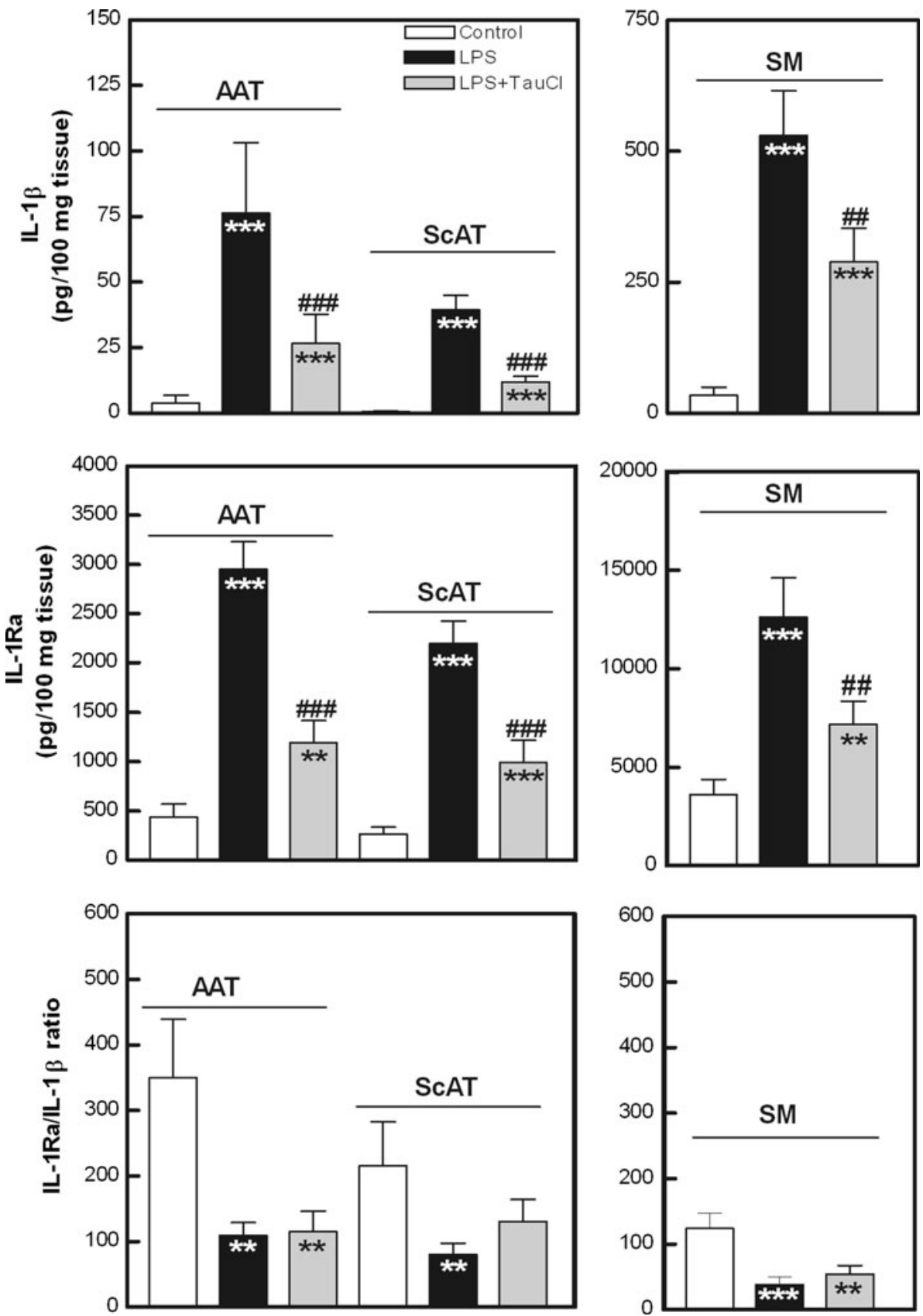

from all tested tissues was similar. In adipose explant cultures, LPS significantly up-regulated leptin release, and addition of TauCl counteracted the LPS effect, while in SM cultures this adipokine secretion was not affected by the treatment. By contrast to leptin, LPS failed to exert any effect on the release of adiponectin. However, in the presence of $\mathrm{TauCl}$, all tissues secreted significantly more adiponectin than both untreated or LPS-treated explants.

Based on the above findings, we report for the first time that $\mathrm{TauCl}$ is a potent inhibitor of LPS-triggered proinflammatory cytokine (IL- $1 \beta$, IL-6, IL-8, TNF- $\alpha$ ) secretion by joint-associated adipose tissues. Although TauCl exerted weaker inhibitory effect on SM secretory activity, suggesting that this compound has limited capability for termination of synovitis, down-regulation of IL- 6 and IL- $1 \beta$ was observed. This is an important finding, as TNF- $\alpha$, IL- $1 \beta$ and IL-6 all play a critical role in RA pathogenesis and are potent activators of cells present in SM. For this reason, therapy of RA by neutralization of these cytokines by biological drugs is being pursued (Scott 2012). Unfortunately, TauCl reduced IL-1Ra release. Due to this effect, residual IL-1 $\beta$ could not be controlled efficiently. However, in all tested tissues, TauCl did not inhibit the production of IL-10, a cytokine of known anti-inflammatory properties. Therefore, 
Fig. 8 Effect of $\mathrm{TauCl}$ on the release of classical adipokines from articular adipose tissue (AAT), subcutaneous (ScAT) adipose tissue and synovial membrane $(S M)$ explants. Explanations as in Fig. 1. Values are the mean and SEM of $54(A A T), 20-23(S c A T)$ or 25-28 (SM) experiments
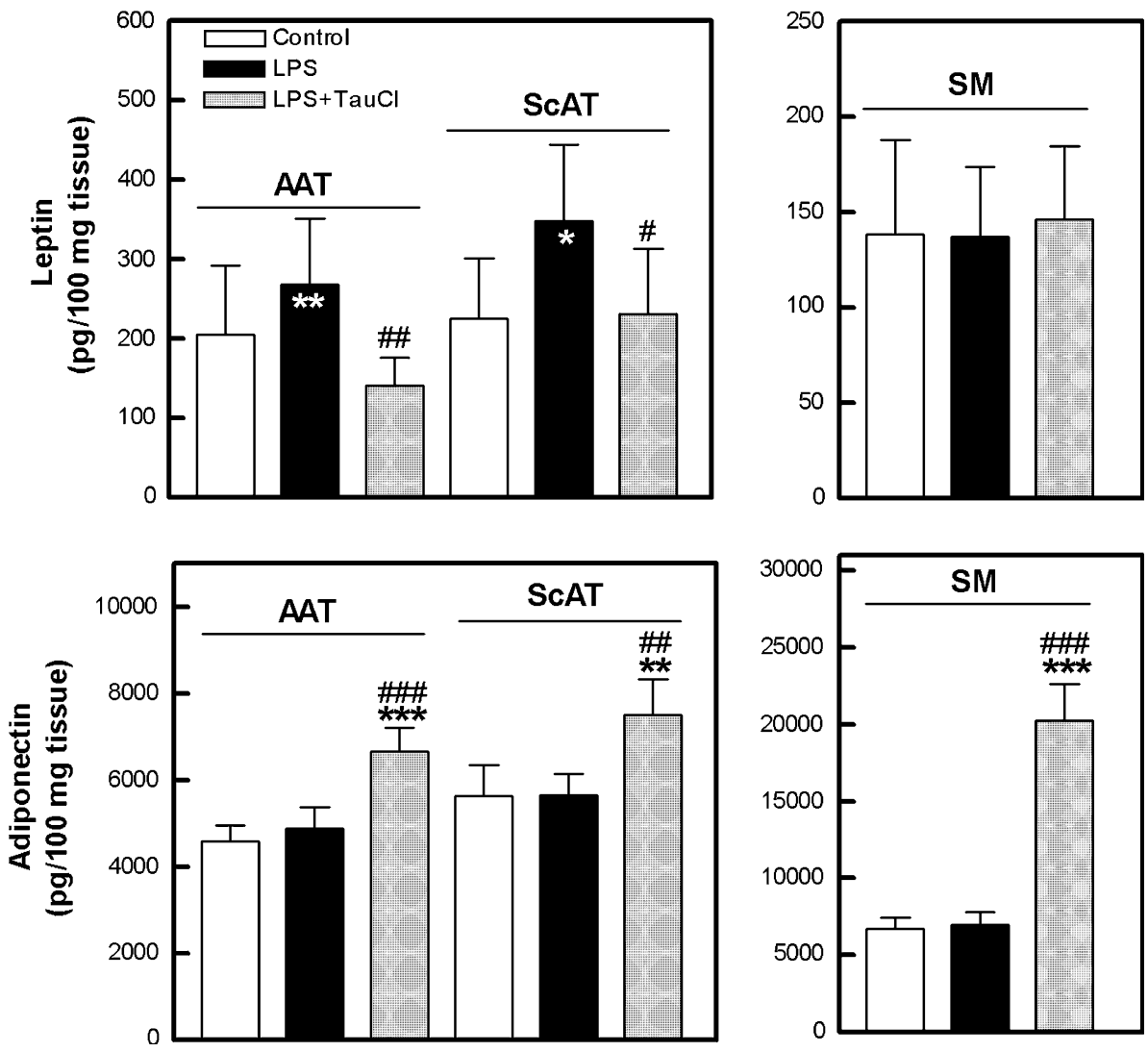

it is likely that the net local effect of $\mathrm{TauCl}$ is anti-inflammatory. Moreover, $\mathrm{TauCl}$ modifies classical adipokine secretion by inhibiting leptin and enhancing adiponectin release. As the role of these adipokines in RA pathology is far from clear, the net effect of this $\mathrm{TauCl}$ action on local pathological processes is unpredictable at the moment. Nevertheless, the present results expand the spectrum of known anti-inflammatory activities of $\mathrm{TauCl}$ and give further support to considering this compound as a promising candidate for RA treatment. However, it should be underlined that the above effects observed upon $\mathrm{TauCl}$ treatment cannot be attributed only to the direct action of this compound, because $\mathrm{TauCl}$ may react with the culture medium components, resulting in the formation of other chloramines. Thus, the contribution of the newly formed chloramines and their decomposition products cannot be excluded.

Taurine chloramine in collagen-induced arthritis (CIA)

There are reports showing that administration of $\mathrm{TauCl}$ improves the course of arthritis in various experimental animal models. Therapeutic benefits have been ascribed to both anti-inflammatory and connective tissue protective action of this compound. For example, intraperitoneal $\mathrm{TauCl}$ administration modified adjuvant-induced arthritis in rats due to down-regulation of the inflammatory mediators (histamine and oxygen radical species) generation (Wojtecka-Łukasik et al. 2005). On the other hand, in septic arthritis induced by intra-articular injection of a single dose of Staphylococcus aureus, locally administered $\mathrm{TauCl}$ exerted an inhibitory effect on the development of bone and cartilage damage in the infected joint, but no beneficial effects were observed when bacteria and $\mathrm{TauCl}$ were administered systemically (Verdrengh and Tarkowski 2005). Collagen-induced arthritis (CIA) is an experimental model of RA, studied extensively to elucidate the pathogenic mechanisms of the disease and to identify potential therapeutic targets. In genetically susceptible (DBA 1/J) mice, the disease can be induced by immunization with native type II collagen in adjuvant. We have previously shown that systemic administration of $\mathrm{TauCl}$ either delayed CIA onset or significantly reduced the incidence of the disease, depending on whether $\mathrm{TauCl}$ therapy is applied early (after primary immunization) or late (after booster immunization) during the CIA course, respectively (Kwaśny-Krochin et al. 2002). Thus, we concluded that systemic application of $\mathrm{TauCl}$ could not alleviate the symptoms of arthritis, but may prevent CIA development. Recently, others (Wang et al. 2011) have reported that $\mathrm{TauCl}$ administered in the same way significantly attenuated the severity of CIA symptoms, i.e., synovial inflammation, cartilage damage and bone erosion. Moreover, in 
the joints of TauCl-treated mice, the number of osteoclasts was reduced and in vitro $\mathrm{TauCl}$ inhibited osteoclastogenesis, supporting the idea that this compound exerts protective effect on the bone. Although the precise mechanisms underlying $\mathrm{TauCl}$ inhibition of CIA are not fully understood and require further studies, the above data support the proposal that $\mathrm{TauCl}$ may be a useful candidate for complementary arthritis treatment. However, to improve therapeutic effectiveness, the stability of $\mathrm{TauCl}$ should be increased. Recently, C-methylated derivatives of $\mathrm{TauCl}$ with better stability at room temperature have been obtained (Low et al. 2009; Shiau et al. 2008). In addition, a synthetic derivative of taurine-bis(1,1-dioxoperhydro1,2,4-thiabiazin-4-yl)methane, named taurolidine (TRD) is another potential candidate for RA therapy. Owing to its bactericidal, anti-inflammatory, antiangiogenic and antitumor properties, TRD has been used in the treatment of patients with peritonitis, sepsis or gastrointestinal and nervous system tumors (Schneider et al. 2005; Willatts et al. 1995; McCourt et al. 2000). In several European countries, TRD is currently licensed for intraperitoneal use for the treatment of peritonitis, and clinical trials evaluating TRD potential antineoplastic benefits are currently underway (Neary et al. 2010). The mechanism of TRD action is not fully understood. Taurolidine is in vivo degraded to methylol-containing products, which exert antibacterial, antiendotoxin and antiadherence activities, and taurine, which is devoid of such properties. It is likely that in vivo TRD-originated taurine may react with $\mathrm{HOCl}$ to produce anti-inflammatory $\mathrm{TauCl}$, but TRD can exert anti-inflammatory effect also by other mechanisms (Willatts et al. 1995; Marcinkiewicz et al. 2006a, b; Neary et al. 2010). Importantly, intraperitoneal treatment with TRD reduced the incidence of CIA in mice, while intra-articular application of TRD resulted in amelioration of ovalbumininduced arthritis in rabbits (Marcinkiewicz et al. 2007).

\section{Summary}

- The fundamental role of taurine in the immune system is related to its antioxidant properties. Taurine protects tissues from oxidative stress associated with the pathology of various inflammatory diseases.

- Taurine, the component (or modulator) of the myeloperoxidase-halide system of leukocytes, reacts with $\mathrm{HOCl} / \mathrm{HOBr}$ to produce taurine haloamines (TauCl/ $\mathrm{TauBr}$ ), which are less toxic milder oxidants, but retain antimicrobial and anti-inflammatory properties.

- Taurine and taurine haloamines are components of innate immunity. The physiological functions of TauCl/ $\mathrm{TauBr}$ are associated with the MPO-halide system of neutrophils.
In conclusion, both in vitro and in vivo studies as well as clinical trials give support to consider taurine and taurine derivatives as potential drugs in human medicine, including infectious and chronic inflammatory disease. However, further studies are necessary to improve their therapeutic effectiveness, especially in the treatment of biofilm-associated infections.

Acknowledgments We want to thank Prof. Waldemar Gottardi and Prof. Marcus Nagl from the Division of Hygiene and Medical Microbiology, Innsbruck Medical University, Austria, for giving us $\mathrm{N}$-chlorotaurine sodium salt and Maria Walczewska for technical assistance. This paper was supported by the Jagiellonian University Medical College grant No (K/ZDS/001008). Dr Ewa Kontny's work was supported by the grant No I/21 from the Institute of Rheumatology, Warsaw.

Open Access This article is distributed under the terms of the Creative Commons Attribution License which permits any use, distribution, and reproduction in any medium, provided the original author(s) and the source are credited.

\section{References}

Bartok B, Firestein GS (2010) Fibroblast-like synoviocytes: key effector cells in rheumatoid arthritis. Immunol Rev 233:233-255

Barua M, Liu Y, Quinn MR (2001) Taurine chloramine inhibits inducible nitric oxide synthase and TNF-alpha gene expression in activated alveolar macrophages: decreased NF-kappaB activation and IkappaB kinase activity. J Immunol 167(4):2275-2281

Bouckenooghe T, Remacle C, Reusens B (2006) Is taurine a functional nutrient? Curr Opin Clin Nutr Metab Care 9:728-733

Chorąży-Massalska M, Kontny E, Kornatka A, Rell-Bakalarska M, Marcinkiewicz J, Maśliński W (2004) The effect of taurine chloramine on pro-inflammatory cytokine production by peripheral blood mononuclear cells isolated from rheumatoid arthritis and osteoarthritis patients. Clin Exp Rheumatol 22(6):692-698

Costeron JW, Stewart PS, Greenberg EP (1991) Bacterial biofilms: a common cause of persistent infections. Science 284:1318-1322

Detert J, Pischon N, Burmester GR, Buttgereit F (2010) The association between rheumatoid arthritis and periodontal disease. Arthritis Res Ther 12:218

Firestein GS (2009) Etiology and pathogenesis of rheumatoid arthritis. In: Firestein GS, Budd RC, Harris T, McInnes IB, Ruddy S, Sergent JS (eds) Kelly's textbook of rheumatology, 8th edn. Saunders Elsevier, Philadelphia, pp 1035-1086

Frommer KW, Zimmermann B, Meier FM, Schröder D, Heil M, Schäffler A, Büchler C, Steinmeyer J, Brentano F, Gay S, Müller-Ladner U, Neumann E (2010) Adiponectin-mediated changes in effector cells involved in the pathophysiology of rheumatoid arthritis. Arthritis Rheum 62:2886-2899

Gabay C, Lamacchia C, Palmer G (2010) IL-1 pathways in inflammation and human diseases. Nat Rev Rheumatol 6:232-241

Gaut JP, Yeh GC, Tran HD, Byun J, Henderson JP, Richter GM, Brennan ML, Lusis AJ, Belaaouaj A, Hotchkiss RS, Heinecke JW (2001) Neutrophils employ the myeloperoxidase system to generate antimicrobial brominating and chlorinating oxidants during sepsis. Proc Natl Acad Sci 98:11961-11966

Gierut A, Perlman H, Pope RM (2010) Innate immunity and rheumatoid arthritis. Rheum Dis Clin North Am 36:271-296

Gottardi W, Nagl M (2010) N-chlorotaurine, a natural antiseptic with outstanding tolerability. J Antimicrob Chemother 65:399-409 
Gottardi W, Hagleitner M, Nagl M (2005) N, N-dichlorotaurine: chemical and bactericidal properties. Arch Pharm (Weinheim) 338(10):473-483

Green TR, Fellman JH, Eicher AL, Pratt KL (1991) Antioxidant role and subcellular localisation of hypotaurine and taurine in human neutrophils. Biochim Biophys Acta 1073:91-97

Gregersen PK, Silver J, Winchester RJ (1987) The shared epitope hypothesis. An approach to understanding the molecular genetics of susceptibility to rheumatoid arthritis. Arthritis Rheum 30:178-182

Gustafson B (2010) Adipose tissue, inflammation and atherosclerosis. J Atheroscler Thromb 17:332-341

Henderson JP, Byun J, Williams MV et al (2001) Production of brominating intermediates by myeloperoxidase. J Biol Chem 11:7867-7875

Huxtable RJ (1992) Physiological actions of taurine. Physiol Rev 72:101-163

Jang JS, Piao S, Cha YN, Kim Ch (2009) Taurine chloramine activates Nrf2, increases HO-1 expression and protects cells from death caused by hydrogen peroxide. J Clin Biochem Nutr 45:37-43

Jeon SH, Lee MY, Rahman MM, Kim SJ et al (2009) The antioxidant, taurine reduced lipopolysaccharide (LPS)-induced generation of ROS, and activation of MAPKs and Bax in cultured pneumocytes. Pulm Pharmacol Ther 22:562-566

Jong CJ, Azuma J, Schaffer SW (2011) Role of mitochondrial permeability transition in taurine deficiency-induced apoptosis. Exp Clin Cardiol 16(4):125-128

Joo K, Lee Y, Choi D, Han J, Hong S, Kim YM, Jung Y (2009) An anti-inflammatory mechanism of taurine conjugated 5-aminosalicylic acid against experimental colitis: taurine chloramine potentiates inhibitory effect of 5-aminosalicylic acid on IL1beta-mediated NFkappa $\beta$ activation. Eur $\mathbf{J}$ Pharmacol 618(1-3):91-97

Kim C, Cha YN (2009) Production of reactive oxygen and nitrogen species in phagocytes is regulated by taurine chloramine. Adv Exp Med Biol 643:463-472

Kim C, Park E, Quinn MR, Schuller-Levis G (1996) The production of superoxide anion and nitric oxide by cultured murine leukocytes and the accumulation of TNF- $\alpha$ in the conditioned media is inhibited by taurine chloramine. Immunopharmacology 34(2-3):89-95

Kim C, Choi HS, Kim JW (2006) Taurine chloramine inhibits the production of nitric oxide and superoxide anion by modulating specific mitogen-activated protein kinases. Adv Exp Med Biol 583:493-498

Kim KS, Park EK, Ju SM, Jung HS, Bang JS, Kim C, Lee YA, Hong SJ, Lee SH, Yang HI, Yoo MC (2007) Taurine chloramine differentially inhibits matrix metalloproteinase 1 and 13 synthesis in interleukin-1beta stimulated fibroblast-like synoviocytes. Arthritis Res Ther 9:R80. doi:10.11.86/ar2279

Kim C, Jang JS, Cho MR, Agarawal SR, Cha YN (2010a) Taurine chloramine induces heme oxygenase-1 expression via Nrf2 activation in murine macrophages. Int Immunopharmacol 10(4):440-446

Kim KS, Choi HM, da Oh H, Kim C, Jeong JS, Yoo MC, Yang HI (2010b) Effect of taurine chloramine on the production of matrix metalloproteinases (MMPs) in adiponectin- or IL-1beta-stimulated fibroblast-like synoviocytes. J Biomed Sci 17(Suppl 1):S27

Klamt F, Shacter E (2005) Taurine chloramine, an oxidant derived from neutrophils, induces apoptosis in human B lymphoma cells through mitochondrial damage. J Biol Chem 280(22):2134621352

Klebanoff SJ (1968) Myeloperoxidase-halide-hydrogen peroxide antibacterial system. J Bacteriol 95:2131-2138
Klebanoff SJ (2005) Myeloperoxidase: friend and foe. J Leukoc Biol 77:598-625

Klein-Wieringa IR, Kloppenburg M, Bastiaansen-Jenniskens YM, Yusuf E, Kwekkeoopm JC, El-Bannoudi H, Nelissen RG, Zuurmond A, Stojanovic-Susulic V, Van Osch GJ, Toes RE, Ioan-Facsinay A (2011) The infrapetellar fat pad of patients with osteoarthritis has an inflammatory phenotype. Ann Rheum Dis 70:851-857

Kontny E, Grabowska A, Kowalczewski J, Kurowska M, Janicka I, Marcinkiewicz J, Maśliński W (1999) Taurine chloramine inhibition of cell proliferation and cytokine production by rheumatoid arthritis fibroblast-like synoviocytes. Arthritis Rheum 42:2552-2560

Kontny E, Szczepańska K, Kowalczewski J, Kurowska M, Janicka I, Marcinkiewicz J, Maśliński W (2000) The mechanism of taurine chloramine inhibition of cytokine (IL-6, IL-8) production by rheumatoid arthritis fibroblast-like synoviocytes. Arthritis Rheum 43:2169-2177

Kontny E, Wojtecka-Łukasik E, Rell-Bakalarska K, Dziewczopolski W, Maśliński W, Maślinski S (2002) Impaired generation of taurine chloramine by synovial fluid neutrophils of rheumatoid arthritis patients. Amino Acids 23:415-418

Kontny E, Maśliński W, Marcinkiewicz J (2003a) Anti-inflammatory activities of taurine chloramine: implication for immunoregulation and pathogenesis of rheumatoid arthritis. Adv Exp Med Biol 526:329-340

Kontny E, Rudnicka W, Kowalczewski J, Marcinkiewicz J, Maślinski W (2003b) Selective inhibition of cyclooxygenase-2-generated prostaglandin E2 synthesis in rheumatoid arthritis synoviocytes by taurine chloramine. Arthritis Rheum 48:1551-1555

Kontny E, Chorąży-Massalska M, Rudnicka W, Janicka I, Marcinkiewicz J, Maśliński W (2003c) The effect of taurine and its metabolites on the pathogenic functions of rheumatoid arthritis fibroblast-like synoviocytes. Centr Eur J Immunol 28:167-172

Kontny E, Rudnicka W, Chorazy-Massalska M, Marcinkiewicz J, Maśliński W (2006a) Taurine chloramine inhibits proliferation of rheumatoid arthritis synoviocytes by triggering a p53dependent pathway. Inflamm Res 55:446-455

Kontny E, Chorąży-Massalska M, Rudnicka W, Marcinkiewicz J, Maśliński W (2006b) Cytotoxicity of taurine metabolites depends on the cell type. Adv Exp Med Biol 583:157-171

Kontny E, Chorazy-Massalska M, Rudnicka W, Marcinkiewicz J, Maśliński W (2007) Comparison of taurine chloramine and taurine bromamine effects on rheumatoid arthritis synoviocytes. Amino Acids 32(3):447-452

Kontny E, Plebanczyk M, Lisowska B, Olszewska M, Maldyk P, Maslinski W (2012) Comparison of rheumatoid articular adipose and synovial tissue reactivity to proinflammatory stimuli: contribution to adipocytokine network. Ann Rheum Dis 71:262-267

Kwaśny-Krochin B, Bobek M, Kontny E, Gluszko P, Biedroń R, Chain BM, Maśliński W, Marcinkiewicz J (2002) Effect of taurine chloramine, the product of activated neutrophils, on the development of collagen-induced arthritis in DBA $1 / \mathrm{J}$ mice. Amino Acids 23:419-426

Learn DB, Fried VA, Thomas EL (1990) Taurine and hypotaurine content of human leukocytes. J Leukoc Biol 48:174-182

Low E, Nair S, Shiau T, Belisle B, Debabov D, Celeri C, Zuck M, Najafi R, Georgopapadakou N, Jain R (2009) N,N-dichloroaminosulfonic acids as novel topical antimicrobial agents. Bioorg Med Chem Lett 19(1):196-198

Maher SG, Condron CEM, Bouchier-Hayes DJ, Toomey DM (2005) Taurine attenuates CD3/interleukin-2-induced $\mathrm{T}$ cell apoptosis in an in vitro model of activation-induced cell death (AICD). Clin Exp Immunol 139:279-286 
Mainnemare A, Mégarbane B, Soueidan A, Daniel A, Chapple IL (2004) Hypochlorous acid and taurine- $N$-monochloramine in periodontal diseases. J Dent Res 83(11):823-831

Marcinkiewicz J (2009) Taurine bromamine: a new therapeutic option in inflammatory skin diseases. Polish Arch Internal Med 119:673-675

Marcinkiewicz J, Kontny E (2012) Taurine, taurine derivatives and immune system. In: A El Idrissi, W L'Amoreaux (eds) Taurine in health and disease, Transworld Research Network Chapter 6, 2011: 000-000 ISBN:978-81-7895-520-9

Marcinkiewicz J, Grabowska A, Bereta J, Stelmaszyńska T (1995a) Taurine chloramine a product of activated neutrophils, inhibits in vitro the generation of nitric oxide and other macrophage inflammatory mediators. J Leukoc Biol 58:667-674

Marcinkiewicz J, Grabowska A, Bereta J, Stelmaszyńska T (1995b) Taurine chloramine a product of activated neutrophils, inhibits in vitro the release of tumor necrosis factor in activated RAW 264.7 cells. J Leukoc Biol 54:119

Marcinkiewicz J, Grabowska A, Bereta J, Bryniarski K, Nowak B (1998) Taurine chloramine down-regulates the generation of murine neutrophil inflammatory mediators. Immunopharmacology $40(1): 27-38$

Marcinkiewicz J, Chain B, Nowak B et al (2000) Antimicrobial and cytotoxic activity of hypochlorous acid: interactions with taurine and nitrite. Inflamm Res 49:280-289

Marcinkiewicz J, Mak M, Bobek M, Biedroń R, Białecka A, Koprowski M, Kontny E, Maśliński W (2005) Is there a role of taurine bromamine in inflammation? Interactive effects with nitrite and hydrogen peroxide. Inflamm Res 54(1):42-49

Marcinkiewicz J, Biedroń R, Białecka A et al (2006a) Susceptibility of Propionibacterium acnes and Staphylococcus epidermidis to killing by MPO-halide system products. Implication for taurine bromamine as a new candidate for topical therapy in treating acne vulgaris. Arch Immunol Ther Exp 54(1):61-68

Marcinkiewicz J, Kurnyta M, Biedroń R, Bobek M, Kontny E, Maśliński W (2006b) Anri-inflammatory effects of taurine derivatives (taurine chloramine, taurine bromamine, and taurolidine) are mediated by different mechanisms. Adv Exp Med Biol 583:481-492

Marcinkiewicz J, Głuszko P, Kontny E, Kwaśny-Krochin B, Bobek M, Wierzchowski W, Ciszek M, Maśliński W (2007) Is taurolidine a candidate for treatment of rheumatoid arthritis? Clin Exp Rheumatol 25:211-218

Marcinkiewicz J, Wojas-Pelc A, Walczewska M, Lipko-Godlewska S, Jachowicz R, Maciejewska A, Białecka A, Kasprowicz A (2008) Topical taurine bromamine, a new candidate in the treatment of moderate inflammatory acne vulgaris. Eur $\mathrm{J}$ Dermatol 18:433-439

Marcinkiewicz J, Walczewska M, Olszanecki R, Bobek M, Biedroń R, Dulak J, Józkowicz A, Kontny E, Maślinski W (2009) Taurine haloamines and heme oxygenase-1 cooperate in the regulation of inflammation and attenuation of oxidative stress. Adv Exp Med Biol 643:439-450

Martini C, Hammerer-Lercher A, Zuck M, Jekle A, Debabov D, Anderson M, Nagl M (2012) Antimicrobial and anticoagulant activities of $\mathrm{N}$-chlorotaurine, $\mathrm{N}, \mathrm{N}$-dichloro-2,2-dimethyltaurine, and $\mathrm{N}$-monochloro-2,2-dimethyltaurine in human blood. Antimicrob Agents Chemother 56(4):1979-1984

McCourt M, Wang JH, Sookhai S, Redmond HP (2000) Taurolidine inhibits tumor cell growth in vitro and in vivo. Ann Surg Oncol 7:685-691

Muż B, Kontny E, Marcinkiewicz J, Maśliński W (2008) Heme oxygenase-1 participates in the anti-inflammatory activity of taurine chloramine. Amino Acids 35:397-402

Nagl M, Teuchner B, Pöttinger E, Ulmer H, Gottardi W (2000a) Tolerance of $\mathrm{N}$-chlorotaurine, a new antimicrobial agent, in infectious conjunctivitis: a phase II pilot study. Ophthalmologica 214(2):111-114

Nagl M, Hess MW, Pfaller K, Hengster P, Gottardi W (2000b) Bactericidal activity of micromolar $N$-chlorotaurine: evidence for its antimicrobial function in the human defense system. Antimicrob Agents Chemother 44:2507-2513

Nagl M, Lass-Flörl C, Neher A, Gunkel A, Gottardi W (2001) Enhanced fungicidal activity of $\mathrm{N}$-chlorotaurine in nasal secretion. J Antimicrob Chemother 47(6):871-874

Nagl M, Nguyen VA, Gottardi W et al (2003) Tolerability and efficacy of $\mathrm{N}$-chlorotaurine in comparison with chloramine T for treatment of chronic leg ulcers with a purulent coating: a randomized phase II study. Br J Dermatol 149:590-597

Neary PM, Hallihan P, Wang JH, Pfirrmann RW, Bouchier-Hayes DJ, Redmond HP (2010) The evolving role of taurolidine in cancer therapy. Ann Surg Oncol 17:1135-1143

Neher A, Gstöttner M, Nagl M, Scholtz A, Gunkel AR (2007) $\mathrm{N}$-chlorotaurine-a new safe substance for postoperative ear care. Auris Nasus Larynx 34(1):19-22

Neumann E, Fromer KW, Vasile M, Müller-Ladner U (2011) Adipocytokines as diving forces in rheumatoid arthritis and related inflammatory diseases? Arthritis Rheum 63:1159-1169

O'Toole GA, Kaplan HB, Kolter R (2000) Biofilm formation as microbial development. Annu Rev Microbiol 54:49-79

Oliveira MWS, Minotto JB, de Oliveira MR et al (2010) Scavenging and antioxidant potential of physiological taurine concetrations against different reactive oxygen/nitrogen species. Pharm Raports 62:185-193

Olszanecki R, Marcinkiewicz J (2004) Taurine chloramine and taurine bromamine induce heme-oxygenase- 1 in resting and LPS-stimulated J774.2 macrophages. Amino Acids 27:29-35

Olszanecki R, Kurnyta M, Biedroń R, Chorobik P, Bereta M, Marcinkiewicz J (2008) The role of heme oxygenase-1 in downregulation of PGE2 production by taurine chloramine and taurine bromamine in $\mathrm{J} 774.2$ macrophages. Amino Acids 35(2):359-364

Park E, Quinn MR, Wright CE, Schuller-Levis G (1993) Taurine chloramine inhibits the synthesis of nitric oxide and the release of tumor necrosis factor in activated RAW 264.7 cells. J Leukoc Biol 54(2):119-124

Park E, Schuller-Levis G, Quinn MR (1995) Taurine chloramine inhibits production of nitric oxide and TNF-alpha in activated RAW 264.7 cells by mechanisms that involve transcriptional and translational events. J Immunol 154:4778-4784

Park E, Schuller-Levis G, Jia JH, Quinn MR (1997) Preactivation exposure of RAW 264.7 cells to taurine chloramine attenuates subsequent production of nitric oxide and expression of iNOS mRNA. J Leukoc Biol 61(2):161-166

Park E, Quinn MR, Schuller-Levis G (2000) Taurine chloramine attenuates the hydrolytic activity of matrix metalloproteinase-9 in LPS-activated murine peritoneal macrophages. Adv Exp Med Biol 483:389-398

Quinn MR, Barua M, Liu Y, Serban V (2003) Taurine chloramine inhibits production of inflammatory mediators and iNOS gene expression in alveolar macrophages, a tale of two pathways: part I, NF-kappaB signaling. Adv Exp Med Biol 526:341-348

Redmond $\mathrm{P}$ et al (1998) Immunonutrition: the role of taurine. Nutrition 14:599-614

Rosen H, Klebanoff SJ, Yi Wang et al (2009) Methionine oxidation contributes to bacterial killing by myeloperoxidase system of neutrophils. PNAS 106(44):18686-18691

Ryter SW, Otterbein LE, Morse D, Choi AM (2002) Heme oxygenase carbon monoxide signaling pathways: regulation and functional significance. Mol Cell Biochem 234-235(1-2):249-263

Schaffer SW, Azuma J, Mozaffari M (2009) Role of antioxidant activity of taurine in diabetes. Can J Physiol Pharmacol 87:91-99 
Scherer HU, Burmester GR (2011) Adaptive immunity in rheumatic diseases: bystander or pathogenic player? Best Pract Res Clin Rheumatol 25:785-800

Schett G, Coates LC, Ash ZR, Finzel S, Conaghan PG (2011) Structural damage in rheumatoid arthritis, psoriatic arthritis, and ankylosing spondylitis: traditional views, novel insights gained from TNF blockade, and concepts for the future. Arthritis Res Ther 13(suppl 1):S4

Schneider A, Cack U, Rothe K, Bennek J (2005) Peritoneal taurolidine lavage in children with localized peritonitis due to appendicitis. Pediatr Surg Int 21:445-448

Schuller-Levis GB, Park E (2004) Taurine and its chloramine: modulators of immunity. Neurochem Res 29(1):117-126

Schuller-Levis G, Metha PD, Rudelli R, Struman J (1990) Immunologic consequences of taurine deficiency in cats. J Leukoc Biol 47:321-331

Scott DL (2012) Biologics-based therapy for the treatment of rheumatoid arthritis. Nature 91:30-43

Shiau TP, Houchin A, Nair S, Xu P, Low E, Najafi RR, Jain R (2008) Stieglitz rearrangement of $N, N$-dichloro-beta, beta-disubstituted taurines under mild aqueous conditions. Bioorg Med Chem Lett 19(4):1110-1114

Shimizu M, Zhao Z, Ishimoto Y, Satsu H (2009) Dietary taurine attenuates dextran sulfate sodium (DSS)-induced experimental colitis in mice. Adv Exp Med Biol 643:265-271

Smith J (1994) Neutrophils, host defence, and inflammation: a double-edged sword. J Leukoc Biol 56:672-686

Stofkova A (2009) Leptin and adiponectin: from energy and metabolic dysbalance to inflammation and autoimmunity. Endocr Regul 43:157-168

Sturmann JA (1993) Taurine in development. Physiol Rev 73:119-147
Thomas EL (1979) Myeloperoxidase, hydrogen peroxide, chloride antimicrobial system: effect of exogenous system on antibacterial action against Escherichia coli. Infect Immun 25:110-114

Thomas EL, Bozeman PM, Jefferson MM et al (1995) Oxidation of bromide by the human leukocyte enzymes myeloperoxidase and eosinophil peroxidase. J Biol Chem 270:2906-2913

Verdrengh M, Tarkowski A (2005) Inhibition of septic arthritis by local administration of taurine chloramine, a product of activated neutrophils. J Rheumatol 32:1513-1517

Wagener FA, Volk HD, Willis D, Abraham NG et al (2003) Different faces of the heme-heme oxygenase system in inflammation. Pharmacol Rev 55:551-571

Wang L, Na Zhao, Fang Zhang, Wang Yue, Liang M (2009) Effect of taurine on leukocyte function. Eur J Pharmacol 616:275-280

Wang Y, Cha YN, Kim KS, Kim C (2011) Taurine chloramines inhibits osteoclastogenesis and splenic lymphocyte proliferation in mice with collagen-induced arthritis. Eur $\mathrm{J}$ Pharmacol 668:325-330

Weiss SJ (1988) Tissue destruction by neutrophils. N Engl J Med 320:365-376

Weiss SJ, Klein R, Slivka A et al (1982) Chlorination of taurine by human neutrophils: evidence for hypochlorous acid generation. J Clin Invest 70:598-603

Willatts S, Radford S, Leitermann M (1995) Effect of antiendotoxic agent, taurolidine, in the treatment of sepsis syndrome: a placebocontrolled, double-blind trial. Crit Care Med 23:1033-1039

Wojtecka-Łukasik E, Gujski M, Roguska K, Maslinska D, Maslinski S (2005) Taurine chloramine modifies adjuvant arthritis in rats. Inflamm Res 54(suppl 1):S21-S22

Yazdanbakhsh M, Eckmann CM, Roos D (1987) Killing of schistosomula by taurine chloramine and taurine bromamine. Am J Trop Med Hyg 37:106-110 